\title{
Rentabilidade na semeadura cruzada da cultura da soja
}

\author{
Paulo R. A. Silva ${ }^{1}$, Leandro A. F. Tavares ${ }^{2}$, Saulo F. G. de Sousa ${ }^{3}$, \\ Tiago P. da S. Correia ${ }^{4} \&$ Neilor B. Riquetti ${ }^{5}$
}

\section{Palavras-chave:}

custo operacional arranjo espacial de plantas produtividade

\begin{abstract}
R E S U M O
O plantio cruzado da soja consiste em semear a área em duas passadas de modo que a segunda fique perpendicular à primeira, formando um tabuleiro de xadrez. Desta forma, o objetivo do trabalho foi avaliar a produtividade e os custos de produção da cultura da soja quando semeada em diferentes arranjos de semeadura cruzada. O experimento foi realizado nas safras 2011/2012 e 2012/2013, em área cultivada em sistema de plantio direto. O delineamento experimental foi em blocos casualizados com 5 tratamentos e 8 repetições. Os tratamentos foram: semeadura em linhas paralelas com adubação e população de plantas recomendada; semeadura cruzada com população e adubo em dobro; semeadura cruzada com população recomendada e adubo em dobro; semeadura cruzada com população em dobro e adubação recomendada; semeadura cruzada com população de plantas e adubo recomendado. Os resultados mostraram maior produtividade para o tratamento de semeadura cruzada com população de plantas em dobro e adubo recomendado; apesar disto, a semeadura convencional em linhas paralelas apresenta maior receita líquida do que a semeadura cruzada da soja sendo, então, mais rentável para o produtor.
\end{abstract}

\section{Key words:}

operating costs

plants spatial arrangement productivity

\section{Soybean rentability in cross-seeding}

\begin{abstract}
A B S T R A C T
Soybean cross-seeding tillage came from better spatial arrangement of plants per area, so some producers have opted for this tillage system, which consists in seeding the area in two steps, forming a chessboard with perpendicular lines of tillage. This study aims to analyse the soybean productivity and production costs when it planted in different dispositions of crossed tillage. The experiment was conducted during the harvests 2011/2012 and 2012/2013 at Lageado Farm of the FCA/UNESP, Botucatu-SP, in an area cultivated under no-tillage. The experimental design was in randomized block with five treatments and eight replications. The treatments were: seeding in parallel rows with recommended fertilization and recommended plant population (conventional); cross-seeding with doubled fertilization and doubled plant population; cross-seeding with recommended plant population and doubled fertilization; cross-seeding with doubled plant population and recommended fertilization; cross-seeding with fertilization and recommended plant population. The results showed statistical difference among the treatments, with increased productivity for the cross-seeding with doubled plant population and recommended fertilization. However the conventional tillage with parallel lines shows higher net earnings than soybean crossseeding, being more profitable for producer.
\end{abstract}

Protocolo 052-2014 - 19/02/2014 • Aprovado em 24/10/2014 • Publicado em 26/01/2015

${ }^{1}$ Departamento de Engenharia Rural/FCA Unesp. Botucatu, SP. E-mail: arbex@fca.unesp.br (Autor correspondente)

${ }^{2}$ Departamento de Engenharia Rural/FCA Unesp. Botucatu, SP. E-mail: leandrotavares@fca.unesp.br

${ }^{3}$ Departamento de Engenharia Rural/FCA Unesp. Botucatu, SP. E-mail: saulo@fca.unesp.br

${ }^{4}$ Departamento de Engenharia Rural/FCA Unesp. Botucatu, SP. E-mail: tiago@fca.unesp.br

${ }^{5}$ Departamento de Engenharia Rural/FCA Unesp. Botucatu, SP. E-mail: neilorbugoni@yahoo.com.br 


\section{INTRODUÇÃo}

A densidade de semeadura é amplamente estudada com a cultura da soja cujo intuito é definir a melhor população de plantas para cada tipo de cultivar disponível porém estudos experimentais sobre o arranjo espacial das plantas não são realizados com a mesma intensidade sendo a semadura cruzada de soja, um exemplo prático.

De acordo com Lima et al. (2012), este tipo de semeadura é observado nas margens de áreas de cultivo como forma compensatória das falhas de locais de manobras e início de semeadura mas são realizadas de maneira empírica. Os autores definem a semadura cruzada como a distribuição de sementes em linhas paralelas às linhas de semeadura convencional realizada anteriormente sendo uma nova semeadura sobre a mesma área, com as linhas formando ângulos de $90^{\circ}$. Neste sistema de semeadura ocorre uma duplicação do número de sementes, fertilizantes e horas trabalhadas da máquina por hectare.

Freitas et al. (2010) verificaram que o aumento da densidade de semeadura não proporcionou maiores rendimentos para a cultura da soja; entretanto, essa constatação foi feita somente para semeadura convencional não sendo estudada em semeadura cruzada.

Na cultura da soja o espaçamento entre linhas interfere na população e no crescimento de plantas daninhas, no índice de área foliar, na velocidade de fechamento das entrelinhas e no rendimento de grãos (Bianchi et al., 2010) porém pouco se tem estudado sobre os custos de produção que compõem as operações agrícolas inseridas neste contexto.

Piacentini et al. (2012), relatam que o acompanhamento sistemático do desempenho das máquinas agrícolas e os cálculos dos seus custos operacionais, são fatores fundamentais para o uso racional. De acordo com Peloia \& Milan (2010), a mecanização agrícola representa um fator de grande importância para a redução de custos na agricultura brasileira sendo o segundo fator mais significativo, inferior apenas à posse da terra; em termos de potencial para redução dos custos de produção, a mecanização é o principal fator.

Segundo Simões et al. (2011), o conhecimento do custo operacional de máquinas é de suma relevância no processo de tomada de decisão auxiliando, de forma fundamental, o controle e o planejamento da utilização desses equipamentos; em geral, tais custos são expressos em termos de unidade de horas efetivas de trabalho da máquina.

O custo de produção é a soma dos valores de todos os recursos utilizados no processo produtivo de uma atividade agrícola. A estimativa dos custos está ligada à gestão da tecnologia, ou seja, à alocação eficiente dos recursos produtivos e ao conhecimento dos preços desses recursos (Clemente et al., 2010).

Em termos econômicos, a questão relativa ao curto ou longo prazo se refere à possibilidade de variação dos fatores de produção. Considera-se curto prazo se pelo menos um dos fatores de produção não puder variar no período considerado quando, no longo prazo, todos os fatores podem variar (Castro et al., 2009).

Ao se falar em custos, deve-se definir os conceitos em termos econômicos. O custo econômico considera os custos explícitos, que se referem ao desembolso efetivamente realizado e os custos implícitos que dizem respeito àqueles para os quais não ocorrem desembolsos efetivos, como é o caso da depreciação e do custo de oportunidade, que se referem ao valor que determinado fator poderia receber em algum uso alternativo (Castro et al., 2009).

O conhecimento e a aplicação de critérios técnicos e econômicos para obtenção dos custos de produção são extremamente importantes para o setor agroflorestal pois permitem que os custos estimados apresentem solidez e sejam confiáveis proporcionando, desta forma, uma competitividade melhor de mercado (Simões \& Silva, 2012).

Segundo Menegatti \& Barros (2007), o empresário agrícola é um tomador de decisão, muitas vezes intuitivamente buscando, entre os diversos processos e recursos produtivos, a melhor alocação de insumos considerando-se que a meta dos pontos chave de qualquer processo produtivo, é determinar o que, quanto e como produzir.

Tendo em vista a importância da cultura da soja para o agronegócio global, a nova tendência de semeadura cruzada da cultura pode ser uma alternativa economicamente vantajosa para os produtores.

O objetivo deste trabalho foi avaliar a produtividade de grãos de soja e os custos de produção para semeadura convencional e cruzada da cultura.

\section{Material e Métodos}

O experimento foi conduzido durante dois anos, nas safras 2011/2012 e 2012/2013, na Fazenda Experimental Lageado, pertencente à Faculdade de Ciências Agronômicas - UNESP, localizada no município de Botucatu, SP, na região centro oeste do Estado de São Paulo cujas coordenadas geográficas são Latitude $22^{\circ} 51^{\prime}$ S e Longitude $48^{\circ} 26^{\prime} \mathrm{W}$ de Greenwich, altitude média de $770 \mathrm{~m}$, clima subtropical chuvoso, apresentando inverno seco, tipo Cfa, de acordo com o critério de Köeppen.

A análise estatística foi realizada conjuntamente, ou seja, os dados obtidos no ano agrícola 2012/2013 foram tabulados e analisados juntamente com os resultados obtidos no ano agrícola 2012/2013. O delineamento experimental foi blocos casualizados, composto por 5 tratamentos e 8 repetições que consistiam em 40 parcelas experimentais. Os tratamentos contavam com diferentes doses de adubo e diferentes populações de plantas, sendo:

T1. Semeadura em linhas paralelas com adubação e população de plantas recomendada (convencional)

T2. Semeadura cruzada com população e adubo em dobro

T3. Semeadura cruzada com população recomendada e adubo em dobro

T4. Semeadura cruzada com população em dobro e adubação recomendada

T5. Semeadura cruzada com população de plantas e adubo recomendado

A variedade de soja utilizada foi BMX Potência RR, recomendada para região na densidade de 17 sementes por metro em espaçamento de $0,45 \mathrm{~m}$ entre linhas. $\mathrm{Na}$ adubação de base, recomendada conforme análise de solo, utilizaram-se $325 \mathrm{~kg} \mathrm{ha}^{-1}$ do fertilizante NPK 00-20-20. 
Na semeadura do experimento foram utilizados um trator marca New Holand, modelo TL110 de $110 \mathrm{cv}$ de potência no motor e semeadora-adubadora de precisão pneumática marca Jumil, com 7 linhas espaçadas a 0,45 m.

Foi colhido $1 \mathrm{~m}^{2}$ de cada parcela manualmente para determinação da produtividade; o restante da área das parcelas foi colhido com Colhedora Autopropelida marca Massey Ferguson, modelo MF3640 com $120 \mathrm{cv}$ de potência no motor e comprimento da plataforma de 4,5 m. Após a debulha das vagens e obtenção da massa de grãos, as amostras foram levadas à estufa e mantidas a temperatura de $65^{\circ} \mathrm{C}$ por $72 \mathrm{~h}$ até atingir massa constante, sendo determinando o teor de água dos grãos e a produtividade calculada com correção para $13 \%$ de teor de água.

Para a aplicação dos defensivos agrícolas foi utilizado um pulverizador marca Jacto modelo vortex, com tanque de 600 $\mathrm{L}$ de capacidade e $12 \mathrm{~m}$ de barra, acoplado a um trator de pneu marca Massey Ferguson, modelo MF283 com $86 \mathrm{cv}$ de potência no motor.

Para o manejo da cultura da soja foi realizado primeiro o tratamento das sementes utilizando-se inseticida Thiamethoxam e fungicida Carboxina + Tiram. Quando do seu controle, as plantas daninhas, principalmente brachiaria, em pré e pós-emergência foram controladas com herbicida Glifosato. Durante o desenvolvimento da cultura houve incidência de lagartas e percevejos, controlados com inseticida Cipermetrina e Acetamiprido + Alfa-cipermetrina respectivamente. Para prevenção e controle de Oídio, Antracnose e Ferrugem-da-soja foi utilizado fungicida Piraclostrobina + Epoxiconazol.

O cálculo do balanço econômico teve, como base, a metodologia desenvolvida pela ASAE (2003). A receita total considerada foi o valor obtido com a venda dos grãos produzidos e os custos de produção foram compostos das despesas com insumos agrícolas e mecanização dos sistemas de produção da cultura, sendo organizados da seguinte forma:

- Operação com máquinas e implementos
a) Hora máquina
b) Manutenção
c) Depreciação
d) FAST (Fator de alojamento seguros e taxas)
- Defensivos
- Fertilizantes
- Sementes

Para o cálculo da receita total foi considerado o valor de $\mathrm{R} \$ 0,53 \mathrm{~kg}^{-1}$ de grãos de soja, baseado no boletim $\mathrm{n}^{\circ} 109$ do IEA (2013). O cálculo dos custos de operação com tratores e implementos foi feito de acordo com a metodologia de custo operacional da ASAE (2003).

Para calcular o valor do hectare trabalhado pelas máquinas, foram considerados os seus valores iniciais de aquisição com cotações realizadas na região de Botucatu-SP, sua vida útil e a quantidade de horas trabalhadas de cada equipamento, que foram considerados segundo definições da ASAE (2003).

O valor da taxa de juros foi definido em $6 \%$ ao ano e o FAST em $1 \%$ ao ano, com eficiência operacional de $75 \%$ para todas as operações e eficiência gerencial de $60 \%$.
A jornada de trabalho foi definida em 8 horas diárias e velocidade de deslocamento do conjunto de $7 \mathrm{~km} \mathrm{~h}^{-1}$ para todas as operações. Para o cálculo do custo operacional ( $\mathrm{R} \$$ $\mathrm{ha}^{-1}$ ) foram utilizadas as seguintes fórmulas:

$$
\mathrm{CO}=\frac{\mathrm{CH}}{\mathrm{Cco}}
$$

em que:

$$
\begin{gathered}
\mathrm{CO} \text { - custo operacional, } \mathrm{R} \$ \mathrm{ha}^{-1} \\
\mathrm{CH}-\text { custo horário, } \mathrm{R} \$ \mathrm{~h}^{-1} \\
\mathrm{Cco}-\text { capacidade operacional de campo, ha } \mathrm{h}^{-1} \\
\mathrm{CH}=\mathrm{CFH}+\mathrm{CCB}+\mathrm{CRM} \\
\mathrm{CFH}=\frac{\mathrm{CFA}}{\mathrm{NHTa}} \\
\mathrm{CFA}=\mathrm{Vi}[\mathrm{Dpa}+(\mathrm{Ja} \times \mathrm{i})+\mathrm{FAST}+\mathrm{Vi}] \\
\mathrm{NHTa}=\frac{\mathrm{Vuh}}{\mathrm{Vua}} \\
\mathrm{CCB}=\mathrm{Fc} \times \mathrm{Pn} \times \mathrm{Pi} \\
\mathrm{CRM}=\mathrm{FRM} \times \frac{\mathrm{Vi}}{\mathrm{Vuh}}
\end{gathered}
$$

em que:

$\mathrm{CH}$ - custo horário, $\mathrm{R} \$ \mathrm{~h}^{-1}$

$\mathrm{CFH}$ - custo fixo horário, $\mathrm{R} \$ \mathrm{~h}^{-1}$

CCB - custo com combustível, $\mathrm{R} \$ \mathrm{~h}^{-1}$

CRM - custo com reparos e manutenção, $\mathrm{R} \$ \mathrm{~h}^{-1}$

CFA - custo fixo anual, R\$ $a^{-1}$

NHTa - número de horas trabalhadas por ano

Vi - valor inicial (aquisição)

Dpa - depreciação anual, R\$

Ja - juro anual, \%

i - taxa de juros, \%

FAST - fator de alojamentos, seguros e taxas, \%

Vuh - vida útil em horas

Vua - vida útil em anos

$\mathrm{Fc}$ - fator de consumo $0,12 \mathrm{~L} \mathrm{cv}^{-1}$

$\mathrm{Pn}$ - potência do motor, cV

$\mathrm{Pi}$ - preço do combustível, $\mathrm{R} \$ \mathrm{~L}^{-1}$

FRM - fator de reparos e manutenção, \%

Para o cálculo do custo com insumos agrícolas (sementes, defensivos e fertilizantes), foram computados todos os valores gastos com os mesmos durante o ciclo de cultivo da soja. De forma semelhante às máquinas, os valores dos insumos foram considerados conforme o mercado da região de Botucatu-SP, e o custo dado em $\mathrm{R} \$ \mathrm{ha}^{-1}$.

Os resultados obtidos foram submetidos à análise de variância a 5\% de significância e as médias foram comparadas pelo teste de Tukey a 0,05 de probabilidade. Os resultados referentes à receita e ao custo de produção foram analisados através de estatística descritiva. 


\section{Resultados e Discussão}

$\mathrm{Na}$ Tabela 1 estão descritos os valores dos insumos (sementes e adubos) utilizados durante o experimento para cada tratamento em questão. É possível observar que o T2 apresenta custo total superior aos demais tratamentos devido à maior utilização de adubos e sementes que são necessárias na semeadura cruzada utilizando-se população de sementes e adubo em dobro.

O custo total de insumos do T1 ( $\left.\mathrm{R} \$ 850,30 \mathrm{ha}^{-1}\right)$ condiz com o custo de $\mathrm{R} \$ 898,34 \mathrm{ha}^{-1}$ publicado pelo IMEA (2013) referente à safra de soja 2012/2013, diferindo apenas pelo fato do IMEA incluir adjuvante e corretivo de solo (calcário) no cálculo dos custos, itens não utilizados neste trabalho e, portanto, não contabilizados nos custos.

Os tratamentos T2, T3 e T4 possuem custos elevados com insumos, reflexo do maior consumo de fertilizantes e/ou sementes do sistema de produção aos quais foram submetidos.

Em sua pesquisa, Tsunechiro et al. (2007), observaram que os insumos (fertilizantes, defensivos e sementes) representaram $65,3 \%$ do COT, semelhante aos resultados obtidos neste trabalho.

De acordo com a Figura 1, os custos operacionais nos sistemas de semeadura cruzada são superiores ao sistema convencional, sendo 50,78\% mais oneroso que o T1. Este maior custo operacional nas semeaduras cruzadas é resultado do maior uso do trator de $110 \mathrm{cv}$ e da semeadora-adubadora, as máquinas submetidas a este sistema de semeadura necessitam de maior consumo de combustível, manutenções e hora máquina.

Exceto o tratamento T1 (sistema convencional/linhas paralelas), os demais tratamentos, por se tratar de semeadura cruzada, sinalizam a necessidade de duas operações com trator e semeadora-adubadora na mesma área ocasionando custos dobrados com essas máquinas.

Tabela 1. Insumos e custo total de insumos (CT) utilizados na soja em semeadura convencional e cruzada

\begin{tabular}{|c|c|c|c|c|c|c|}
\hline \multirow{2}{*}{ Trat. } & \multirow{2}{*}{\multicolumn{2}{|c|}{$\frac{\text { Sementes Adubos }}{\left(\mathbf{k g ~ h a}^{-1}\right)}$}} & \multicolumn{3}{|c|}{ Defensivos $\left(\mathrm{L} \mathrm{ha}^{-1}\right)$} & \multirow{2}{*}{$\begin{array}{c}\text { CT } \\
\left(R \$ \mathrm{ha}^{-1}\right)\end{array}$} \\
\hline & & & Herbicida & Inseticida & Fungicida & \\
\hline T1 & 60 & 325 & 3 & 0,5 & 1 & $850,30 \mathrm{C}$ \\
\hline T2 & 120 & 650 & 3 & 0,5 & 1 & $1578,30 \mathrm{~A}$ \\
\hline T3 & 120 & 32 & 3 & 0,5 & 1 & 1168 \\
\hline T 4 & 60 & 650 & 3 & 0,5 & 1 & 1260 \\
\hline T5 & 60 & 325 & 3 & 0,5 & 1 & $850,30 \mathrm{C}$ \\
\hline
\end{tabular}

T1 - Semeadura em linhas paralelas com adubação e população de plantas recomendada (convencional); T2 - Semeadura cruzada com população e adubo em dobro; T3 - Semeadura cruzada com população recomendada e adubo em dobro; T4 - Semeadura cruzada com população em dobro e adubação recomendada; T5 - Semeadura cruzada com população de plantas e adubo recomendado.

Médias seguidas de mesma letra não diferem entre si pelo teste de Tukey, a nível de 0,05 de probabilidade

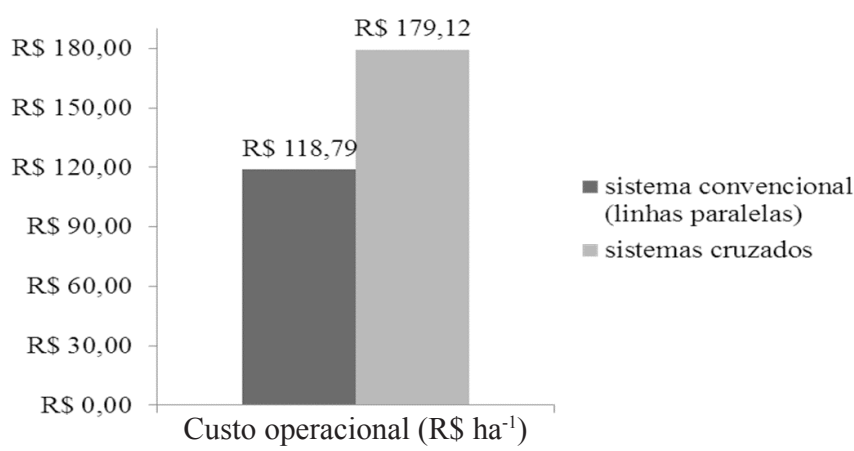

Figura 1. Comparação do custo operacional com máquinas e implementos para sistema convencional e sistema cruzado de semeadura da soja
Os custos operacionais com máquinas agrícolas são apresentados na Tabela 2 sendo a semeadura cruzada mais onerosa que a semeadura convencional.

De acordo com a Tabela 2, a semeadura cruzada apresentou custo operacional total, de $\mathrm{R} \$ 189,60 \mathrm{ha}^{-1}$, sendo $59,5 \%$ mais onerosa que a semeadura convencional o que significa dizer que elevou os custos e pode gerar prejuízos. O elevado custo operacional neste sistema de semeadura ocorre em virtude da realização de duas operações de semeadura em uma mesma área.

Para realizar a semeadura convencional o conjunto trator de $110 \mathrm{cv}$ e semeadora-adubadora apresentam custo operacional de $\mathrm{R} \$ 33,98$ e R $\$ 67,96$ ha $^{-1}$, respectivamente. Para semear cruzando sobre as linhas da semeadura convencional e formar a semeadura cruzada, o conjunto trator de $110 \mathrm{cv}$ e semeadoraadubadora tem seus custos operacionais dobrados passando a custar R \$ 67,96 e R \$73,64 ha-1, respectivamente.

A Tabela 3 mostra os resultados de produtividade obtidos pelo experimento ocorrendo diferença estatística significativa entre os tratamentos T2 e T4, ambos de semeadura cruzada.

A maior produtividade, $4976,55 \mathrm{~kg} \mathrm{ha}^{-1}$ de grãos de soja foi verificada no T4 (semeadura cruzada com população em dobro e adubação recomendada), sendo significativamente maior que a produtividade de $4326,20 \mathrm{~kg} \mathrm{ha}^{-1}$ obtida no T2 (Semeadura cruzada com população e adubo em dobro).

Do tratamento T2 ao T5, todos de semeadura cruzada, nenhum apresentou produtividade significativamente diferente do T1, que representa semeadura convencional sendo, assim, independente da forma de semeadura cruzada, este sistema de semeadura não influencia a produtividade de grãos de soja quando comparado à semeadura convencional da cultura.

Lichtenberg \& Smith-Ramírez (2011) observaram, trabalhando com soja transgênica, que o sistema de plantio

Tabela 2. Máquinas utilizadas no cultivo de soja e seus custos operacionais $\left(\mathrm{R} \$ \mathrm{ha}^{-1}\right)$ no sistema de semeadura convencional e cruzada

\begin{tabular}{lcc}
\hline \multirow{2}{*}{ Máquinas } & \multicolumn{2}{c}{ Custo operacional (R\$ ha') } \\
\cline { 2 - 3 } & \multicolumn{2}{c}{ Semeadura } \\
\cline { 2 - 3 } Trator $110 \mathrm{cv}$ & Convencional & Cruzada \\
\hline Trator $86 \mathrm{cv}$ & 33,98 & 67,96 \\
Semeadora-adubadora & 6,92 & 6,92 \\
Pulverizador & 36,82 & 73,64 \\
Colhedora & 26,35 & 26,35 \\
Custo operacional total & 14,73 & 14,73 \\
\hline
\end{tabular}

Tabela 3. Produtividade (PROD), receita total (RT), custo total $(C T)$ e receita líquida $(R L)$ da semeadura de soja em semeadura convencional e cruzada

\begin{tabular}{ccccc}
\hline \multirow{2}{*}{ Tratamentos } & $\begin{array}{c}\text { PROD } \\
\left.\mathbf{( k g ~ h a}^{-1}\right)\end{array}$ & $\mathbf{R T}$ & $\mathbf{C T}$ & $\mathbf{R L}$ \\
\cline { 3 - 5 } T 1 & $4941,20 \mathrm{AB}$ & $2.618,83$ & 969,09 & $1.649,74$ \\
T 2 & $4326,20 \mathrm{~B}$ & $2.292,88$ & 1757,42 & 535,46 \\
T 3 & $4566,55 \mathrm{AB}$ & $2.420,27$ & 1347,42 & $1.072,85$ \\
T 4 & $4976,55 \mathrm{~A}$ & $2.637,57$ & 1439,42 & $1.198,15$ \\
T 5 & $4715,00 \mathrm{AB}$ & $2.498,95$ & 1029,42 & $1.469,53$ \\
\hline
\end{tabular}

T1 - Semeadura em linhas paralelas com adubação e população de plantas recomendada (convencional); T2 - Semeadura cruzada com população e adubo em dobro; T3 - Semeadura cruzada com população recomendada e adubo em dobro; T4 - Semeadura cruzada com população em dobro e adubação recomendada; T5 - Semeadura cruzada com população de plantas e adubo recomendado.

Médias seguidas de mesma letra não diferem entre si pelo teste de Tukey, a 0,05 de probabilidade 
convencional em linhas paralelas apresenta maior rentabilidade quando comparado ao sistema de plantio com soja convencional.

$\mathrm{O}$ tratamento $\mathrm{T} 2$ apresentou as menores receitas sendo a maior receita total verificada no $\mathrm{T} 4$ e maior receita líquida encontrada no T1.

$\mathrm{O}$ tratamento $\mathrm{T} 2$ apresentou a menor receita bruta e receita líquida em função de ter a menor produtividade, condição inversa ao tratamento $\mathrm{T} 1$, que teve maior produtividade e as maiores receitas. $\mathrm{O}$ tratamento $\mathrm{T} 2$ apresenta receita líquida $67,5 \%$ menor que o $\mathrm{T} 1,535,46 \mathrm{R} \$ \mathrm{ha}^{-1}$ ante $1.649,74 \mathrm{R} \$ \mathrm{ha}^{-1}$, em razão de ter mantido a população de plantas e adubação recomendadas, ocasionando a colocação dobrada de sementes e adubo na mesma área no momento em que se semeia cruzando; o mesmo ocorre com os valores de consumo de combustível, hora máquina e manutenção, elevando os custos operacionais.

O tratamento que apresentou melhor produtividade foi o T4; entretanto, não apresentou a melhor receita líquida pois o fato de manter a adubação recomendada e cruzar a semeadura, se assemelha ao ocorrido com o tratamento T2, em que houve consumo dobrado de adubo por hectare e custo operacional elevado com máquinas.

Entre os tratamentos com semeadura cruzada a melhor receita líquida foi proporcionada pelo T5; este tratamento manteve a população de plantas e a adubação recomendadas por hectare, realizando apenas o cruzamento das linhas de semeadura. Este fato foi conseguido reduzindo-se, pela metade, as dosagens recomendadas dos insumos por metro de linha visto que ao cruzar as linhas se conseguiu manter a população de plantas e a dosagem de adubo recomendado. O único fator que onerou os custos em relação ao T1 de melhor custo, foi o custo operacional com as máquinas.

\section{Conclusões}

1. A maior produtividade obtida no experimento foi para o tratamento com semeadura cruzada da soja utilizandose população de plantas por hectare em dobro e adubação recomendada.

2. O custo operacional da semeadura cruzada da soja é mais elevado que a semeadura convencional em linhas paralelas.

3. A semeadura convencional em linhas paralelas apresenta maior receita líquida do que a semeadura cruzada da soja sendo, desta forma, mais rentável para o produtor.

\section{Literatura Citada}

ASAE - American Society of Agricultural Engineering. ASAE Standards 2003. Agricultural machinery management. St. Joseph: ASAE. p.366-372. ASAE EP 496. 2.

Bianchi, M. A.; Fleck, N. G.; Lamego, F. P.; Agostinetto, D. Papéis do arranjo de plantas e do cultivar de soja no resultado da interferência com plantas competidoras. Planta Daninha, v.28, p.979-991, 2010. http://dx.doi.org/10.1590/S0100-83582010000500006
Castro, E. R. Teixeira, E. C. ; Figueiredo, A. M. ; Santos, M. L. Teoria dos custos. In: Santos, M. L. ; Lírio, V. S.; Vieira, W. C.Microeconomia aplicada. Visconde do Rio Branco: Suprema, 2009. p.193-234.

Clemente, A.; Gutervil, C.; Taffarel, M. Projeção e aferição de custos nas propriedades rurais familiares do Centro-Sul do Paraná. Custos e Agronegócio, v.6, p.39-59, 2010.

Freitas, M. C. M.; Hamawaki, O. T.; Bueno, M. R.; Marques, M. C. Época de semeadura e densidade populacional de linhagens de soja UFU de ciclo semitardio. Bioscience Journal, v.26, p.698708,2010 .

IEA - Instituto de Economia Agrícola. Preços médios diários recebidos pelos produtores no Estado de São Paulo nos principais escritórios de desenvolvimento rural. São Paulo: ESALQ/BM\&F. 2013. Boletim IEA n.109

IMEA - Instituto Matogrossense de Economia Agropecuária. Custo de produção de soja - safra 2012/13. Base março de 2012. http:// www.imea.com.br/publicacoes.php? categoria $=4 \&$ subcategoria $=3$. 6 Jun.2013.

Lichternberg, E.; Smith Ramírez, R. Slippage in conservation cost sharing. American Journal of Agricultural Economics, v.93, p.113129, 2011. http://dx.doi.org/10.1093/ajae/aaq124

Lima, S. F. ; Alvarez, R. C. F. ; Theodoro, G. F. ; Bavaresco, M. ; Silva K. S. Efeito da semeadura em linhas cruzadas sobre a produtividade de grãos e a severidade da ferrugem asiática da soja. Biocience Journal, v.28, p.954-962, 2012.

Menegatti, A. L.; Barros, A. L. M. Análise comparativa dos custos de produção entre soja transgênica e convencional: um estudo de caso para o Mato Grosso do Sul. Revista de Economia Rural, v.45, p.162-183, 2007.

Peloia, P. R.; Milan, M. Proposta de um sistema de medição de desempenho aplicado à mecanização agrícola. Engenharia Agrícola, v.30, p.681-691, 2010. http://dx.doi.org/10.1590/S010069162010000400012

Piacentini, L.; Souza, E. G.; Opazo, M. A. U.; Nóbrega, L. H. P.; Milan, M. Software para estimativa do custo operacional de máquinas agrícolas maqcontrol1. Engenharia Agrícola, v.32, p.609-623, 2012. http://dx.doi.org/10.1590/S0100-69162012000300020

Simões, D.; Fenner, P. T.; Bantel, C. A. Análise operacional e econômica do processamento de madeira de Eucalitpo com "Hypro" em região montanhosa. Revista Árvore, v.35, p.505-514, 2011. http://dx.doi.org/10.1590/S0100-67622011000300013

Simões, D.; Silva, M. R. da. Desempenho operacional e custos de um trator na irrigação pós-plantio de eucalipto em campo. Revista Ceres, v.59, p.164-170, 2012. http://dx.doi.org/10.1590/S0034737X2012000200003

Tsunechiro, A.; Oliveira, M. D. M.; Furlaneto, F. P. B.; Duarte A. P. Custo e rentabilidade da produção de milho safrinha, em dois níveis tecnológicos. Análises e Indicadores do Agronegócio, v.2, p.1-4, 2007. 